\title{
Imagem do servidor público: um estudo com os usuários do Tribunal de Justiça do Estado de Minas Gerais
}

\author{
Jussara Maria Canuto de Aquino \\ Universidade Fumec \\ Luiz Antônio Antunes Teixeira \\ Universidade Fumec \\ Darly Fernando Andrade \\ Universidade Federal de Uberlândia
}

O objetivo deste trabalho foi analisar a imagem do servidor público do ponto de vista dos usuários do Fórum Lafayette, em Belo Horizonte, local onde se agrupa a maior parte das secretarias da justiça de primeira instância da capital, do Tribunal de Justiça do Estado de Minas Gerais (TJMG). Foram identificados os atributos centrais e periféricos que têm mais importância na formação da imagem do servidor público e a relação entre esses atributos e dimensões da imagem, tais como: cognitiva, simbólica, funcional e emocional. Para isso, pesquisou-se principalmente sobre a temática da imagem, principalmente sob a ótica da Psicologia Cognitiva, bem como da Teoria das Representações Sociais e da Teoria do Núcleo Central, provenientes da Psicologia Social. Por meio deste estudo, foi possível concluir que a imagem do servidor público do Fórum Lafayette, de maneira geral, é positiva. De maneira específica, sob a perspectiva dos advogados, essa imagem é negativa; entretanto, para os cidadãos que figuram como parte em processos judiciais, a imagem é positiva.

Palavras-chave: agente público, perfil profissional, psicologia, setor público, estudo de caso

\section{Imagen de funcionarios públicos: un estudio de los usuarios de la Corte de Justicia del Estado de Minas Gerais}

El objetivo de este estudio es hacer un análisis de la imagen del servidor público desde el punto de vista de los usuarios de Fórum Lafayette, en la ciudad de Belo Horizonte, Brasil, donde se agrupan la mayor parte de los departamentos de justicia de primera instancia de la capital del estado, así como el Tribunal de Justicia del Estado de Minas Gerais. Se

[Artigo recebido em dezembro de 2013. Versão final em abril de 2015.] 
identificaron los atributos centrales y periféricos que son más importantes en la formación de la imagen del servidor público y su relación con las diversas dimensiones de la imagen: cognitiva, simbólica, funcional y emocional. Para esto, se realizaron pesquisas principalmente en el tema de la imagen, sobre todo desde la perspectiva de la Psicología Cognitiva, así como la Teoría de las Representaciones Sociales y la Teoría del Núcleo Central, que son parte de la Psicología Social. A través de este estudio, se concluye que la imagen del funcionario del Fórum Lafayette, en general, es positiva. Específicamente, desde la perspectiva de los abogados, esta imagen es negativa. Sin embargo, para los individuos que son parte en procesos judiciales, la imagen es positiva.

Palabras clave: funcionario público, perfil profesional, psicología, sector público, estudio de caso

Image of Civil Servants: a study with users of the Court of Justice of the State of Minas Gerais

This study is an analysis of the civil servants' image from the point of view of users of the Fórum Lafayette, in the city of Belo Horizonte, Brazil. Most of the departments of first instance justice and trial courts, as well as the Appellate Court of the state of Minas Gerais, are located in Belo Horizonte. The core and peripheral attributes that play the most important role in the development of the image of civil servants were identified, as well as their connection with the various image dimensions (i. e., cognitive, symbolic, functional and emotional). For that purpose, our research focused on the subject of image, especially from the perspective of Cognitive Psychology, as well as the Theory of Social Representations and the Central Nucleus Theory, which belong to the field of Social Psychology. From this study, we can conclude that the image of the civil servant at Fórum Lafayette is, generally speaking, positive. From the specific point of view of attorneys, that image is negative. However, for litigants, that image is positive.

Keywords: public agent, professional profile, psychology, public sector, case study 


\section{Introdução}

A mudança sempre fez parte da humanidade, mas o que parece assustar a todos é a velocidade com que ela vem ocorrendo, principalmente em razão do avanço tecnológico e da globalização. As transformações no panorama mundial abrangem também o cenário das organizações, ocasionando nelas alterações significativas. As empresas privadas tendem a transformar-se, visando à satisfação do cliente, uma vez que esse é o responsável pelos lucros. As organizações públicas também não escapam da necessidade de promover mudanças. A sociedade demonstra cada vez mais exigência em relação aos serviços e à administração estatal. Para corresponder a essa expectativa, o setor público tem adotado alguns norteadores utilizados por empresas privadas, com as devidas adaptações, tendo em vista o alcance de melhorias contínuas e o atendimento eficiente das demandas.

Desde 1980, essas mudanças passaram a ser mais estruturadas, principalmente com a elaboração do Plano Diretor da Reforma do Aparelho do Estado (PDRAE), formulado em 1995, que propõe mudanças para a administração gerencial. Os princípios estabelecidos nesse plano diretor foram direcionados para o aumento da eficiência, da descentralização e da qualidade no atendimento ao cidadão (CHAVES; MARQUES, 2000).

Parte dessas transformações pode ser perceptível pela sociedade por meio da atuação dos servidores públicos. Esse é um dos pontos em relação ao qual é possível associar a imagem do serviço público e a do servidor público. Considerando que serviço público é, de maneira geral, aquele que a administração pública presta à sociedade - uma vez que o reconhece como essencial para a sobrevivência do grupo social e do próprio Estado -, pode-se afirmar que o servidor público é o mediador entre a administração pública e a sociedade.

A ideia de que o servidor público é aquele que deposita o paletó na cadeira e sai ou que fica lixando as unhas durante o expediente fez e ainda pode fazer parte da convicção de muitas pessoas. Mesmo que, atualmente, essa não seja a realidade mais presente, é preciso considerar que as imagens fortemente enraizadas podem causar distorções nas percepções de fenômenos ou objetos sociais. Sendo assim, mesmo diante de mudanças e alterações de cenários, perfis e contextos, uma imagem arraigada pode impedir o discernimento de modificações.

Uma pesquisa sobre imagem possibilita verificar a existência de defasagens entre a realidade concreta e a representação social circulante acerca dessa realidade. Pode contribuir também para o aperfeiçoamento dos serviços que compõem o objeto de estudo, uma vez que identifica aspectos negativos que podem ser revertidos.

Este trabalho objetivou avaliar a imagem do servidor público do ponto de vista dos usuários do Fórum Lafayette, órgão da justiça de primeira instância da capital 
do Tribunal de Justiça do Estado de Minas Gerais (TJMG). Nesse sentido, buscou-se investigar quais os atributos centrais e periféricos da imagem do servidor público, buscando responder à questão: qual a imagem que os usuários do serviço público têm dos servidores públicos?

Para isso, foi necessário identificar os atributos centrais e periféricos que têm importância na formação da imagem do servidor público e a relação entre esses atributos e dimensões da imagem, tais como: funcional, simbólica, cognitiva e emocional.

Para tratar o tema da imagem do servidor público é importante e indispensável esclarecer a noção de imagem. Por se tratar de um fenômeno complexo, é preciso considerar diversas perspectivas a fim de analisá-lo de forma contundente. Entretanto, abordar todas as perspectivas extrapolaria os objetivos deste trabalho. Sendo assim, foram tomadas como base para essa conceituação, principalmente, algumas noções extraídas da Psicologia Cognitiva e da Psicologia Social. Além disso, alguns pontos relativos às funções da imagem também foram importantes para compor e enriquecer o estudo sobre o tema.

\section{Referencial teórico}

\section{Conceito de imagem}

Um estudo sobre a noção de imagem pode ser feito a partir de uma perspectiva interdisciplinar, contemplando-se diversas abordagens, como a da Psicologia Cognitiva, da Psicologia Social, a da Filosofia, a da Psicanálise e a do Marketing (SANTAELLA; NOTH, 2001). Os significados do termo imagem são diversos e variam de acordo com a perspectiva pela qual é visto.

Este trabalho abordou o domínio subjetivo da noção de imagem, o qual se relaciona com o modo particular com que cada indivíduo visualiza e processa as imagens. Para esse fim, foram utilizados como norteadores principais a Teoria das Representações Sociais de Moscovici (1961), a Teoria do Núcleo Central de Abric (1976), ambos da Psicologia Social, e o conceito de modelos mentais, abordado principalmente por Stenberg (2000), da Psicologia Cognitiva.

\section{Psicologia Social e imagem}

Sob a perspectiva da Psicologia Social, o processo de organização da imagem na memória pode ser explicado por meio da Teoria das Representações Sociais (TRS), elaborada por Moscovici, em 1961, e da Teoria do Núcleo Central, considerada uma teoria complementar à anterior, elaborada por Jean-Claude Abric, em 1976.

A expressão representações sociais foi inaugurada por Moscovici, em sua obra La psychanalyse, son image et son public $(1961,1976)$, que discorre sobre a 
representação social da Psicanálise. De acordo com Moscovici (1978), a realidade das representações sociais está presente nas relações sociais estabelecidas pelos indivíduos, nas comunicações trocadas entre eles e nos objetos produzidos ou consumidos por eles.

A partir desse entendimento, pode-se afirmar que a parte qualitativa deste trabalho, a qual visou conhecer o que as pessoas pensam sobre o servidor público, tratou de abordar as representações sociais relacionadas aos servidores públicos. De acordo com Moscovici, essas representações referem-se à visão do senso comum.

Os pressupostos de base do conceito de imagem também não são muito diferentes, apesar de designar uma organização mais coerente e permeada por juízos de valor, de acordo com a ciência Eikonics (palavra inglesa derivada do grego Eikon = imagem, que autoriza a tradução por iconia). A Iconia ou Ciência Icônica é, portanto, o estudo das imagens mentais. Conforme esclarece Moscovici ao comentar essa perspectiva, "imagens são espécies de sensações mentais, de impressões que os objetos e as pessoas deixam em nosso cérebro" (Moscovicl, 1978, p. 47).

De acordo com esse ponto de vista, pode-se inferir que a imagem do servidor público está associada às sensações mentais que foram criadas por meio do contato com ele. Ou seja, uma situação de um atendimento em alguma instituição pública é capaz de gerar impressões sobre os servidores que ficam registradas na memória das pessoas, que passa a funcionar como uma tela seletiva capaz de filtrar o que deve ser percebido. Esse filtro determina, em certa medida, a interpretação a ser dada a mensagens que estejam relacionadas com o servidor público. Entretanto, de acordo com a teoria da representação social, há um constante dinamismo no meio social, alimentado pela interação entre as pessoas, o que faz com que as imagens sejam modificadas continuamente.

As representações sociais são resultantes da interação e da comunicação, já que precisam ser compreendidas a partir do contexto social. Além disso, podem ser denominadas também de sistemas simbólicos construídos no ambiente social, capazes de representar o conhecimento cotidiano das pessoas. Segundo Minayo (2003), as representações sociais são imagens construídas sobre o real e manifestadas por meio de palavras, sentimentos e condutas. Sendo assim, é possível inferir que aquilo que se fala a respeito do servidor público contribui para a formação de uma representação social que lhe diz respeito, interferindo também na imagem constituída em torno dele.

De acordo com a teoria de Moscovici, as representações sociais têm como função favorecer a apropriação do mundo pelo indivíduo, já que oferecem orientações às pessoas sobre o mundo material e o social. Além disso, proporcionam um código comum para que calhem as trocas sociais (JOVCHELOVITCH, 2000). 
Uma função também elucidada por Moscovici é a de que a representação social é um processo psíquico apto para tornar familiar e aproximar o que não é conhecido e o que se encontra a certa distância do indivíduo. É a partir de uma representação social que surge a imagem, que poderá manter-se por algum tempo na memória. Esse tempo varia de acordo com a necessidade de cada pessoa e também com o nível de força e o vigor com que essa imagem surgiu.

A Teoria da Modelagem Associativa explica, por meio dos processos de ancoragem e objetivação, como o indivíduo organiza as imagens. A ancoragem busca reter ideias estranhas, reduzi-las a categorias e a imagens comuns e, assim, inseri-las em um contexto familiar. É, então, nomear aquilo que é estranho, a fim de eliminar sua estranheza e seus aspectos ameaçadores (Moscovıcl, 2007).

Com relação à objetivação, Moscovici (2007, p. 71) define-a como sendo a capacidade de descobrir a qualidade icônica de uma ideia, ou seja, é reproduzir um conceito em uma imagem. A objetivação visa, então, tornar concreto o que até então não existia. É transformar a imagem em uma réplica da realidade (GUARESCHI, 1996; Moscovicl, 2007).

Segundo a Teoria das Representações Sociais, portanto, as imagens são resultantes das construções ideológicas procedentes da sociedade e resultam em modos mais ou menos predeterminados de interpretar a realidade (MoscoviCI, 1978).

Como complemento da Teoria das Representações Sociais de Moscovici, Jean Claude Abric (1976) inseriu o conceito de núcleo central, referente às representações sociais (SÁ, 1996). A Teoria do Núcleo Central assegura que a formação de imagens é um processo dinâmico, no qual o indivíduo utiliza-se de um núcleo central e de um conjunto de elementos periféricos para organizar as informações que recebe do meio em que vive (SÁ, 1996).

O núcleo central, de certa maneira, determina a organização e a significação da representação, na medida em que é composto por elementos cuja falta desestruturaria a representação ou atribuiria a ela um significado totalmente diferente (SÁ, 1996). Nessa perspectiva, a pesquisa qualitativa deste trabalho, uma vez que visou identificar os atributos relacionados aos servidores, pode ser considerada um mecanismo para conhecer o núcleo central da representação social dos servidores públicos.

Os elementos periféricos são considerados os responsáveis pela interface entre a realidade concreta e o sistema central, uma vez que contextualizam e atualizam constantemente as determinações do sistema central. Daí serem tidos como elementos mais flexíveis e capazes de auxiliar na adaptação à realidade sem, no entanto, deixar de proteger o núcleo central (SÁ, 1996).

As teorias de definição de atributos e de atributos característicos também sugerem que a organização de imagens passa por conceitos centrais e por conceitos 
diferenciados. De acordo com a teoria de definição de atributos, a acepção básica de um conceito é formada por alguns atributos que são essenciais e suficientes para evocar tal conceito. Segundo a teoria de atributos característicos, dentro de um conceito existem vários atributos com diferentes graus de importância. Por esse motivo, esses atributos são agrupados em categorias diversas (EYSENCK; KEANE, 1994). Sob esse ponto de vista, este trabalho buscou conhecer quais são os atributos que podem ser considerados constitutivos do núcleo central da representação social dos servidores públicos, pelo fato de serem apreciados como aqueles que têm maior importância na formação da imagem do servidor. Também se buscou verificar quais são os atributos periféricos que têm menor importância para a constituição da imagem.

\section{Psicologia Cognitiva e imagem}

Conforme a perspectiva da Psicologia Cognitiva, imagem é uma construção mental organizada por meio de diversas associações e em torno de elementos centrais que ficam armazenados na memória. Esse processo é denominado representação mental ou modelo mental, resultado da percepção, da imaginação, do conhecimento e da compreensão. Considerando o objeto desta pesquisa, podese dizer que, sob o ponto de vista da Psicologia Cognitiva, a imagem do servidor público é uma construção mental produzida pela percepção, pela imaginação e pelo conhecimento que os usuários têm a respeito do servidor, e que são associadas e armazenadas na memória em torno de elementos centrais. Por meio dos modelos mentais, as pessoas adquirem maneiras de enxergar o mundo e de fazer suposições capazes de influenciar seu próprio comportamento.

Um dos fatores que interferem na formação dos modelos mentais são as experiências sociais. A vivência, o contato ou não com um objeto ou situação e as relações sociais estabelecidas podem determinar a formação de um modelo mental. Daí poder-se afirmar que os modelos mentais são dinâmicos, estão em constante transformação, já que a vida está em movimento constante (STENBERG, 2000). Uma imagem do servidor público pode, portanto, ser alterada se o modelo mental responsável por ela também passar por modificações. O conhecimento, a troca de informação, o contato social, entre outras, são formas que podem auxiliar na alteração de uma imagem.

Diversas teorias surgiram para explicar os tipos de representação mental, tais como: a Teoria de Código Dual de Paivio e a Teoria Proposicional de Anderson (Sternberg, 2000).

A Teoria de Código Dual de Allan Paivio sugere que as representações mentais imaginárias e as representações mentais verbais podem ser consideradas dois códigos distintos. As primeiras correspondem aos códigos análogos e as outras aos 
códigos simbólicos, ou seja, um código para imagens e outro para palavras. Ambos podem ser armazenados e evocados para uso posterior. As imagens mentais são códigos análogos, uma vez que são formadas de maneira análoga aos estímulos físicos oriundos do ambiente. Já as representações mentais para palavras são representadas por códigos simbólicos, pois, para sua formação, são utilizados símbolos arbitrários (palavras e combinações de palavras), visando à representação de ideias. Essa teoria, portanto, sugere que existem dois códigos diferentes (código imaginário analógico e código verbal simbólico) para a representação mental do conhecimento (STENBERG, 2000, p. 156).

Conforme a Teoria Proposicional de John Anderson e Gordon Bower, as representações mentais não são armazenadas na forma de imagens nem de palavras, mas sim de uma proposição, ou seja, uma definição subjacente a uma analogia particular entre conceitos. Sendo assim, as informações, sejam elas imaginárias ou verbais, são codificadas e armazenadas sob a forma de proposições. Para recordar essas informações armazenadas, a representação proposicional é evocada e, a partir dela, o código verbal ou imaginal é recriado na mente do indivíduo com relativa precisão.

\section{Funções da imagem}

As imagens, sejam elas tidas como representações sociais ou mentais, têm funções, e a principal delas é direcionar a ação e as escolhas dos indivíduos, seja com base nos processos culturais ou nos processos cognitivos (DE TONI, 2005). No campo da representação social, Moscovici (2007) descreve as funções de convenção e de prescrição da imagem. No sentido de convencionar, as imagens atribuem forma definida aos objetos, pessoas ou acontecimentos, além de alocá-los em categorias distintas e que, posteriormente, são compartilhadas socialmente. No tocante à função de prescrição, a sociedade, por meio das representações, exerce amplo domínio, a ponto de determinar o que deve ser pensado. Assim, as representações não são criadas, são repensadas, recitadas e reapresentadas. Muitas imagens que as pessoas possuem das outras pessoas e dos acontecimentos são influenciadas, então, pela cultura, que se expressa por meio de normas, valores, hábitos e interpretações. As representações sociais funcionam, então, como receitas que, de certa maneira, contribuem para que o indivíduo oriente-se em sua convivência social (Moscovicl, 2007).

Segundo a perspectiva da teoria das representações mentais, as imagens têm três funções: elas funcionam como um sistema de conviç̧ões, auxiliam na observação e têm poder preditivo. Em relação à primeira função, pode-se afirmar que os modelos mentais são baseados em convicções sobre fenômenos, objetos e pessoas, adquiridas por meio de observações, instruções e inferências. A imagem como observação está relacionada com a correspondência entre o modelo mental acessível e o objeto, 
pessoa ou situação observada. Por último, o poder preditivo da imagem indica a função que tem o modelo mental de predizer ou antecipar um comportamento.

É possível inferir, então, que um mesmo objeto pode apresentar diversas imagens, considerando que cada pessoa utilizará suas representações sociais e seus modelos mentais para formar tais imagens. Desse modo, as imagens podem ser formadas a partir de processos individuais, por meio das representações mentais e de processos sociais, traduzidos pelas representações sociais. Os elementos de ambos os processos relacionam-se e complementam-se. Com base nesse enunciado, e também na revisão dos conceitos de imagem desenvolvidos por Dobni e Zinkhan (1990), De Toni, Milan e Schuler (2005), em pesquisas sobre o assunto, identificaram quatro elementos que consideraram como os mais relevantes para os estudos e por isso são dispostos em dimensões da imagem:

a. Dimensão cognitiva: refere-se aos construtos mentais, racionais e lógicos que os indivíduos utilizam para avaliar uma pessoa, um serviço, um produto ou um objeto. Essa dimensão compreende, então, os pensamentos e percepções das pessoas, bem como os julgamentos que fazem e impressões que elas têm de determinado serviço, prestador de serviço ou objeto (DOBNI; ZINKHAN, 1990; Martineau, 1958; De Toni; Milan; SChuler, 2005).

b. Dimensão funcional: é composta por elementos que geralmente estão relacionados aos aspectos físicos, aos resultados concretos, por exemplo, da prestação de um serviço. É a dimensão que abrange a funcionalidade, a utilidade de um serviço, produto ou prestador de serviço e os benefícios que eles podem proporcionar às pessoas (DE TONI; MILAN; SCHULER, 2005).

c. Dimensão emocional: compreende as emoções e os sentimentos suscitados pelos serviços, produtos ou prestadores de serviço. Remete ao que as pessoas sentem diante, por exemplo, de um servidor público. Refere-se ao registro emocional que as pessoas conservam das experiências (GOLEMAN, 1995).

d. Dimensão simbólica: está relacionada às associações simbólicas, ou seja, aos atributos intangíveis de um produto, serviço ou prestador de serviço. Sendo assim, representa fatores que estão relacionados com valores, padrões sociais e aspectos psicossociais. Nesse caso, a avaliação está baseada no significado (LeVY, 1959; MARTINEAU, 1958).

\section{Metodologia}

A técnica escolhida para aferição dos atributos da imagem do servidor público é uma adaptação da técnica de configuração de imagem de produto (TCIP), método proposto por De Toni (2005) para a mensuração das imagens do produto, baseado 
no método desenvolvido por Schuler (2000) para a identificação da imagem organizacional.

Trata-se de uma pesquisa descritiva que visou levantar opiniões, atitudes e crenças de uma população (GIL, 1995). Quanto ao método, essa pesquisa classificase como do tipo survey. Segundo McDaniel e Gates (2003), esse procedimento técnico envolve um entrevistador que interage com os sujeitos por intermédio de entrevistas, a fim de identificar opiniões e atitudes. Para cumprimento de tal objetivo, foi utilizado um questionário estruturado visando certa padronização no processo de coleta de dados.

A TCIP é dividida em duas fases que são: configuração de conteúdo e configuração de agrupamentos. Neste estudo, essas fases foram realizadas da seguinte forma:

Primeira fase: configuração do conteúdo

Realização de uma pesquisa qualitativa, com o objetivo de identificar, em uma amostra representativa, os atributos principais em torno do termo indutor servidor público do Fórum Lafayette, além de classificar tais atributos nas dimensões funcional, simbólica, cognitiva e emocional. A amostragem foi intencional, composta por 12 usuários do serviço público do Fórum Lafayette, divididos em dois grupos: seis advogados (representantes em processos judiciais) e seis cidadãos que figuravam como parte autora ou ré em processos judiciais. A entrevista foi estruturada, composta por cinco questões. Para cada dimensão da imagem (cognitiva, simbólica, emocional e funcional), existe uma pergunta, visando instigar os respondentes a expor, de maneira espontânea, ideias que o termo indutor servidor público Ihes traz.

Os atributos foram listados e posteriormente analisados por duas pessoas diferentes, que atuaram como juízes para construir uma listagem de atributos que pudessem ser expressos em poucas palavras e que não fossem repetidos. Com base nessa listagem dos atributos, foi construído o questionário para a etapa da pesquisa quantitativa.

Segunda fase: configuração de agrupamentos

A partir da identificação dos atributos, realizada na primeira fase, foi elaborado o questionário para realização da pesquisa quantitativa. Para essa fase, foram entrevistados 250 usuários do serviço público do Fórum Lafayette, que constituíram uma amostra representativa, divididos em dois grupos: 125 advogados (representantes em processos judiciais) e 125 cidadãos que figuravam como parte autora ou ré em processos judiciais. Essa fase objetivou conhecer os atributos centrais e periféricos que têm importância na formação da imagem do servidor público. Além disso, tornou possível conhecer os atributos centrais e periféricos que influenciam a imagem do servidor público. 


\section{Análise e discussão dos dados}

\section{Perfil da amostra}

Com relação ao perfil dessa amostra, as mulheres corresponderam a 50,8\% e os homens a $49,2 \%$ da amostra total. Os respondentes com idade entre 25 e 34 anos representaram $41,6 \%$ da amostra. Aqueles com idade até 24 anos, 11,2\%; de 35 a 44 anos, 28,8\%; de 45 a 55 anos, 12,4\%; acima de 55 anos, 6,0\%. A divisão da amostra por escolaridade demonstrou que a maior parte dos cidadãos $(40,8 \%)$ tinha o 2 o grau completo; $12 \%$ cursavam o superior; $12,8 \%$ tinham completado o ensino superior; $20 \%$ tinham o 1 을 grau completo; e 14,4\% tinham o 1 을 grau incompleto. Os advogados, conforme exigência legal, tinham formação superior.

\section{Análise de dados}

A análise dos resultados se deu por meio da modelagem de equações estruturais. Para tanto, foi utilizado o método Partial Least Squares (PLS), que não exige normalidade multivariada das variáveis e consegue trabalhar com um tamanho de amostra mais reduzido, além de adequar-se melhor a estudos exploratórios do que o método utilizado pelo Lisrel (CHIN, 1998). O software utilizado foi o SmartPLS 2.0 M3.

Inicialmente, de maneira exploratória, as variáveis que compõem cada construto foram selecionadas pela análise de componentes principais (ACP), com a eliminação daquelas que obtiveram baixa comunalidade. Em seguida, foi ajustado o modelo estrutural com as variáveis remanescentes. Nesse ajuste inicial, todas as variáveis que apresentaram cargas fatoriais abaixo de 0,6 foram eliminadas. O modelo resultante é apresentado na Figura 1.

\section{Figura 1: Modelo Estrutural Ajustado}

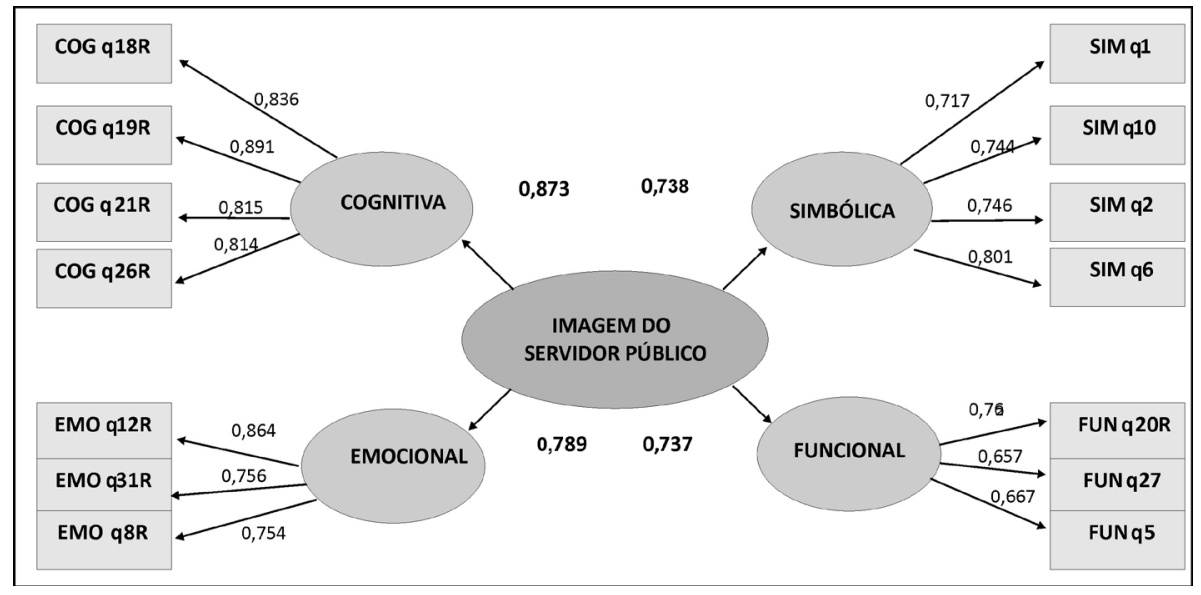

Fonte: Dados da pesquisa. 
Em relação à confiabilidade do construto, Chin (1998) indica que deva ser avaliada, prioritariamente, segundo a confiabilidade composta e que tal valor deve ser superior a 0,7 . Todos os construtos apresentaram valores superiores ao mínimo indicado.

Em relação à validade discriminante, foram avaliadas as cargas cruzadas dos itens com os construtos. Como pode ser observado na Tabela 1, cada item possui carga mais alta com o construto a que pertence do que em qualquer outro, atestando assim a validade discriminante. A validade convergente, por outro lado, está relacionada à magnitude das cargas em relação ao respectivo construto. Todos os itens possuem cargas altas nos seus respectivos construtos (acima de 0,6 ).

Tabela 1: Cargas cruzadas dos itens

\begin{tabular}{c|c|c|c|c}
\hline $\begin{array}{c}\text { Dimensão } \\
\text { da imagem }\end{array}$ & Cognitiva & Emocional & Funcional & Simbólica \\
\hline \multirow{4}{*}{ Cognitiva } & $\mathbf{0 , 8 4}$ & 0,51 & 0,46 & 0,72 \\
\cline { 2 - 5 } & $\mathbf{0 , 8 9}$ & 0,52 & 0,42 & 0,74 \\
\cline { 2 - 5 } & $\mathbf{0 , 8 2}$ & 0,50 & 0,48 & 0,73 \\
\hline \multirow{4}{*}{ Emocional } & $\mathbf{0 , 8 1}$ & 0,54 & 0,46 & 0,72 \\
\cline { 2 - 5 } & 0,52 & $\mathbf{0 , 8 6}$ & 0,47 & 0,71 \\
\hline \multirow{3}{*}{ Funcional } & 0,53 & $\mathbf{0 , 7 6}$ & 0,31 & 0,62 \\
\cline { 2 - 5 } & 0,41 & $\mathbf{0 , 7 5}$ & 0,24 & 0,53 \\
\cline { 2 - 5 } & 0,56 & 0,36 & $\mathbf{0 , 7 6}$ & 0,61 \\
\hline \multirow{4}{*}{ Simbólica } & 0,26 & 0,22 & $\mathbf{0 , 6 6}$ & 0,41 \\
\cline { 2 - 5 } & 0,27 & 0,31 & $\mathbf{0 , 6 7}$ & 0,52 \\
\cline { 2 - 5 } & 0,25 & 0,25 & 0,38 & $\mathbf{0 , 4 9}$ \\
\cline { 2 - 5 } & 0,40 & 0,40 & 0,46 & $\mathbf{0 , 6 2}$ \\
\hline
\end{tabular}

Fonte: Dados da pesquisa.

Com base nos dados da Figura 1, percebe-se que a dimensão cognitiva representa a maior contribuição (o coeficiente de caminho para o construto imagem foi de 0,873), e a funcional, a menor contribuição na composição da imagem do servidor público $(0,737)$. Pode-se inferir, portanto, que a imagem do servidor público do Fórum Lafayette mostra-se mais carregada de constructos mentais, racionais e lógicos, ou seja, com aspectos relacionados a pensamentos, julgamentos, percepções e impressões dos usuários. Em contrapartida, a menor influência na formação da imagem do servidor público refere-se aos aspectos associados à utilidade dele e ao benefício que pode proporcionar aos usuários.

Com relação às dimensões medianas, a emocional apresentou maior representatividade que a simbólica. Isso indica que, para o usuário do serviço público, os aspectos relacionados aos sentimentos e emoções suscitados pelos servidores 
influenciam mais a imagem que produzem do servidor público do que os aspectos relacionados ao intangível, ou seja, relacionados a valores e crenças. Sendo assim, a imagem do servidor público está mais associada à ideia que os usuários fazem desse profissional e menos associada ao que eles significam.

Com base nos resultados encontrados para os itens remanescentes no modelo, realizou-se a multiplicação da carga fatorial de cada um em relação ao coeficiente de caminho da dimensão, indicado na coluna importância, da tabela a seguir. Tais valores foram transformados em percentuais e são, dessa forma, passíveis de classificação por nível de importância, conforme Tabela 2.

Tabela 2: Classificação dos itens remanescentes do modelo em relação ao nível de importância

\begin{tabular}{|c|c|c|c|c|c|c|c|}
\hline & \multirow[b]{2}{*}{ Item } & \multirow[b]{2}{*}{ Atributo } & \multirow[b]{2}{*}{$\begin{array}{l}\text { Coeficiente } \\
\text { de caminho }\end{array}$} & \multirow[b]{2}{*}{$\begin{array}{l}\text { Carga } \\
\text { fatorial }\end{array}$} & \multicolumn{3}{|c|}{ Importância do item } \\
\hline & & & & & Absoluta & $\%$ & $\begin{array}{l}\text { Categorização } \\
\text { em relação à } \\
\text { formação da } \\
\text { imagem }\end{array}$ \\
\hline \multirow{4}{*}{ : } & 18 & Gosta de trabalhar & 0,873 & 0,836 & 0,730 & $8,5 \%$ & Núcleo central \\
\hline & 19 & Não é acomodado & 0,873 & 0,891 & 0,778 & $9,1 \%$ & Núcleo central \\
\hline & 21 & $\begin{array}{l}\text { Não utiliza o direito da } \\
\text { estabilidade que possui para } \\
\text { ser uma pessoa acomodada } \\
\text { no trabalho }\end{array}$ & 0,873 & 0,815 & 0,711 & $8,3 \%$ & Núcleo central \\
\hline & 26 & Não é preguiçoso & 0,873 & 0,814 & 0,711 & $8,3 \%$ & Núcleo central \\
\hline \multirow{3}{*}{ 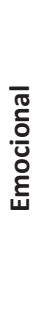 } & 12 & $\begin{array}{l}\text { Não causa sentimentos de } \\
\text { impotência e frustração no } \\
\text { usuário do serviço público }\end{array}$ & 0,789 & 0,864 & 0,682 & $8,0 \%$ & Núcleo central \\
\hline & 31 & $\begin{array}{l}\text { Transmite esperança ao } \\
\text { usuário do serviço público }\end{array}$ & 0,789 & 0,756 & 0,596 & $7,0 \%$ & Periferia \\
\hline & 8 & $\begin{array}{l}\text { Não causa impaciência e } \\
\text { irritabilidade no usuário }\end{array}$ & 0,789 & 0,754 & 0,595 & $7,0 \%$ & Periferia \\
\hline \multirow{3}{*}{$\begin{array}{l}\overline{0} \\
\frac{0}{0} \\
\frac{0}{5} \\
\frac{5}{4}\end{array}$} & 20 & $\begin{array}{l}\text { Traz benefício ao usuário do } \\
\text { serviço público }\end{array}$ & 0,737 & 0,762 & 0,562 & $6,6 \%$ & Periferia \\
\hline & 27 & $\begin{array}{l}\text { Presta atendimento e } \\
\text { fornece informações ao } \\
\text { usuário do serviço público }\end{array}$ & 0,737 & 0,657 & 0,484 & $5,7 \%$ & Periferia \\
\hline & 5 & $\begin{array}{l}\text { Oferece facilidades } \\
\text { (comodidade) ao usuário do } \\
\text { serviço público }\end{array}$ & 0,737 & 0,667 & 0,492 & $5,7 \%$ & Periferia \\
\hline
\end{tabular}




\begin{tabular}{|c|c|c|c|c|c|c|c|}
\hline & \multirow[b]{2}{*}{ Item } & \multirow[b]{2}{*}{ Atributo } & \multirow[b]{2}{*}{$\begin{array}{l}\text { Coeficiente } \\
\text { de caminho }\end{array}$} & \multirow[b]{2}{*}{$\begin{array}{l}\text { Carga } \\
\text { fatorial }\end{array}$} & \multicolumn{3}{|c|}{ Importância do item } \\
\hline & & & & & Absoluta & $\%$ & $\begin{array}{l}\text { Categorização } \\
\text { em relação à } \\
\text { formação da } \\
\text { imagem }\end{array}$ \\
\hline \multirow{5}{*}{ 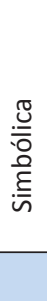 } & 1 & $\begin{array}{l}\text { Oferece ajuda aos usuários } \\
\text { do serviço público }\end{array}$ & 0,738 & 0,717 & 0,529 & $6,2 \%$ & Periferia \\
\hline & 10 & É eficiente & 0,738 & 0,744 & 0,549 & $6,4 \%$ & Periferia \\
\hline & 2 & Ajuda as pessoas carentes & 0,738 & 0,746 & 0,551 & $6,4 \%$ & Periferia \\
\hline & 6 & É competente & 0,738 & 0,801 & 0,591 & $6,9 \%$ & Periferia \\
\hline & & & & TOTAL & 8,561 & $100,0 \%$ & \\
\hline
\end{tabular}

Fonte: Dados da pesquisa.

Com base na análise dos dados da Tabela 2, é possível conhecer o nível de importância de cada um dos atributos que constituem a imagem do servidor público, visando identificar os atributos centrais e periféricos dessa imagem. A mensuração da importância percebida nos atributos é uma maneira de se ter mais informações sobre os dados que compõem a imagem pesquisada. Os atributos com elevada importância fazem parte do núcleo central da imagem, e os atributos com baixo nível de importância formam a periferia da imagem.

A dimensão cognitiva apresenta a maior representatividade, enquanto a dimensão simbólica tem a menor representatividade na formação da imagem do servidor público do Fórum Lafayette. Isso nos permite inferir que o núcleo central da imagem é formado predominantemente por atributos da dimensão cognitiva, uma vez que encontramos apenas um atributo emocional como componente do núcleo central. Além disso, é possível deduzir que todos os atributos referentes às dimensões funcional e simbólica compõem a periferia da imagem, juntamente com dois atributos da dimensão emocional.

Com base nessa análise da classificação, foi possível identificar quais os atributos que formam o núcleo central e a periferia da imagem do servidor público do Fórum Lafayette (Tabela 2).

Como todos os itens do questionário foram mensurados em uma escala de 1 a 5 , para obtenção de estatísticas descritivas, optou-se por ter os escores fatoriais dos construtos na mesma escala de seus indicadores, facilitando assim a interpretação dos resultados. Para tanto, transformaram-se os escores padronizados (análise fatorial) para a escala dos itens. Tal procedimento foi formalizado por Fornell et al. (1996) e é disponibilizado pelo SmartPLS 2.0. 
Tendo como referência o valor 3, que é o ponto central da escala de 1 a 5 , considerou-se que construtos com médias abaixo desse ponto central tiveram avaliações negativas, e acima, avaliações positivas.

Com base no critério supracitado, a imagem do servidor público do Fórum Lafayette é positiva, uma vez que a média é de 3,070, ou seja, acima de 3,0. Destaca-se, porém, que tal média excede muito pouco o limite preestabelecido para avaliações positivas. Com relação às variáveis, pode-se inferir que a imagem do servidor público do Fórum Lafayette é negativa sob o ponto de vista dos advogados $(2,821)$. Já os cidadãos (partes em processos judiciais $-3,319$ ) avaliam a imagem de maneira positiva.

Uma possível explicação para a constatação de que os advogados têm uma imagem negativa dos servidores públicos pode ser o fato de serem pessoas que estão em contato constante com a instituição e com os servidores. A convivência mais próxima permite conhecer aspectos que nem sempre são visíveis para as pessoas que têm um contato menor com os servidores. Além disso, pressupõe-se que os advogados são conhecedores dos trâmites processuais, o que geralmente não ocorre com a maioria dos cidadãos que figuram como parte em processo judicial. O fato de conhecerem as leis e procedimentos jurídicos pode assegurarIhes uma postura mais crítica em relação à atuação dos servidores públicos.

Tabela 3: Síntese da avaliação da imagem do servidor público

\begin{tabular}{c|c|c|c|c}
\hline Média & $\begin{array}{c}\text { Imagem } \\
\text { Geral }\end{array}$ & $\begin{array}{c}\text { Imagem dos } \\
\text { Advogados }\end{array}$ & $\begin{array}{c}\text { Imagem dos } \\
\text { Usuários }\end{array}$ \\
\hline Cognitiva & 3,065 & Positiva & Negativa & Positiva \\
\hline Funcional & 3,342 & Positiva & Positiva & Positiva \\
\hline Emocional & 2,458 & Negativa & Negativa & Negativa \\
\hline Simbólica & 3,374 & Positiva & Positiva & Positiva \\
\hline
\end{tabular}

Fonte: Dados da pesquisa.

De acordo com a Tabela 3, relativa às dimensões da imagem, foi possível constatar que, sob a perspectiva da dimensão cognitiva, ou seja, dos aspectos relacionados a pensamentos, julgamentos, percepções e impressões dos usuários em relação aos servidores, a imagem é positiva para os cidadãos (partes em processos judiciais) e negativa para os advogados. No que tange aos aspectos relacionados aos sentimentos e emoções suscitados pelos servidores, a imagem é negativa para ambos os tipos de usuários. Esse dado fornece a informação de que sentimentos desagradáveis são suscitados nos advogados e cidadãos usuários do serviço do Fórum Lafayette. As dimensões que obtiveram maior média, e por isso 
podem ser consideradas positivas, foram a simbólica e a funcional. A primeira está relacionada aos valores e crenças, ou seja, ao significado que os usuários atribuem aos servidores. A dimensão funcional está associada à utilidade deles e ao benefício que podem proporcionar aos usuários. Considerando que, na classificação das dimensões na formação da imagem, a ordem apresentada foi cognitiva, emocional, simbólica e funcional, e relacionando essa ordem com a avaliação da imagem apresentada na Tabela 3, pode-se concluir que as dimensões que foram mais bem avaliadas (simbólica e funcional) são aquelas que possuem menor influência na formação da imagem do servidor. Em contrapartida, as dimensões com avaliação negativa (emocional e cognitiva) apresentam-se como mais influentes na imagem que os usuários formam do servidor público do Fórum Lafayette.

\section{Conclusão}

Este trabalho demonstrou que a imagem central do servidor público do Fórum Lafayette é composta, em grande parte, pelos atributos cognitivos, ou seja, associada com aspectos relacionados a pensamentos, julgamentos, percepções e impressões dos usuários. Pode-se inferir então que a imagem central do servidor público está relacionada com a percepção dos usuários em relação aos seguintes atributos: gosto pelo trabalho e demonstração de iniciativa, ideia considerada como contrária à acomodação. Consideram também a percepção de que os servidores não se utilizam da estabilidade como justificativa para não buscar desenvolvimento profissional, além da demonstração de não serem preguiçosos. Observou-se também que um dos atributos considerados pelos respondentes como aspectos integrantes da imagem central do servidor público está associado à dimensão emocional. Os usuários também consideram muito importante que os servidores não causem sentimentos de impotência e frustração no usuário do serviço público.

A menor influência na formação da imagem do servidor público referese à dimensão funcional. A imagem periférica do servidor público é formada, principalmente, por atributos associados à utilidade dele para os usuários. Sendo assim, o público pesquisado considerou como tendo menor importância os atributos relacionados com o fato de o servidor público proporcionar benefícios aos usuários, bem como prestar atendimento, fornecer informação e oferecer comodidade (facilidades) aos usuários dos serviços públicos.

As dimensões emocional e simbólica podem ser consideradas medianas em relação à representatividade na formação da imagem do servidor público, apesar de a dimensão emocional ter uma influência um pouco maior. Entretanto, com exceção do atributo central emocional mencionado anteriormente, todos os atributos categorizados nessas duas dimensões formam a imagem periférica do 
servidor público. Portanto os atributos emocionais considerados periféricos, ou seja, aqueles considerados pouco importantes na formação da imagem do servidor público estão relacionados com o fato de o servidor transmitir esperança e não causar sentimentos de impaciência e irritabilidade no usuário. Entre os atributos simbólicos, considerados também periféricos, estão a competência, a eficiência, a capacidade de oferecer ajuda aos usuários e de ajudar as pessoas carentes.

Com relação à avaliação da imagem do servidor público do Fórum Lafayette, foi possível constatar que essa imagem é positiva. Entretanto, é possível observar uma grande lacuna a ser preenchida na busca de excelência dessa imagem, principalmente em relação à avaliação dos usuários advogados, que consideram negativa a imagem do servidor público do Fórum Lafayette.

A compreensão da importância de cada atributo para a imagem do servidor público possibilita ao próprio servidor, bem como aos setores estratégicos do Tribunal de Justiça do Estado de Minas Gerais, concentrar-se naqueles de maior importância e implementar ações que sejam eficazes para a melhoria da imagem. Como a dimensão cognitiva da imagem está negativa para a população de advogados, a instituição pode, por um lado, oferecer ações educacionais que fortaleçam as competências dos servidores, sobretudo as atitudes de comprometimento e proatividade, que podem opor-se à ideia de acomodação que aparece nos construtos cognitivos. Por outro lado, as campanhas publicitárias para o público de advogados devem incluir também os aspectos cognitivos da imagem do servidor. De toda forma, o que parece ser também extremamente significativo é a necessidade de melhorar os aspectos emocionais da imagem do servidor, que estão geralmente associados aos aspectos relacionais no desenvolvimento do trabalho. Nesse sentido, podem auxiliar programas que visem prevenir conflitos na relação entre servidor e usuário, além de melhorar as próprias condições da estrutura do ambiente de trabalho, para se evitar irritação e impaciência tanto do servidor quanto do usuário.

Pode haver uma impossibilidade de separar totalmente a imagem do servidor em relação à imagem da própria instituição. Talvez os aspectos cognitivos da imagem sejam mais facilmente associados ao servidor do que à instituição. Enquanto o usuário pode associar, conscientemente ou não, os aspectos funcionais e emocionais também à instituição e não apenas ao servidor, os aspectos funcionais me pareceram mais passíveis de serem personificados no servidor. De toda forma, é preciso sempre ter em mente que a cultura, as condições de trabalho e a própria natureza da missão institucional são aspectos que auxiliam na construção das representações sociais da imagem do servidor. Não é possível estabelecer uma separação, já que as percepções sobre ambos se alimentam mutuamente. Nesse sentido, muitos aspectos relativos à estrutura do Judiciário, como o acúmulo de 
processos e a morosidade da justiça, serão certamente associados à imagem do servidor público. De modo que não é possível melhorar muito a imagem do servidor público sem melhorar objetivamente o próprio serviço público.

Com vistas à ampliação do estudo dessa temática, é recomendável a realização de trabalhos de caráter gerencial que busquem investigar como melhorar a imagem do servidor público em suas várias dimensões. Além disso, é interessante também que novas pesquisas, embasadas nos atributos que formam o núcleo central e a periferia da imagem, busquem descrever a imagem dos servidores públicos em relação a esses atributos. Ressalta-se também a recomendação de ampliar a amostra para futuros trabalhos, além da indicação de aperfeiçoamento das questões utilizadas para a identificação de atributos. É interessante que elas sejam alteradas, no sentido de se tornarem mais objetivas, tendo em vista representar de maneira mais adequada as dimensões da imagem, principalmente no que diz respeito às dimensões simbólica e funcional.

\section{Referências}

ABRIC, J. C. Pratiques sociales et représentations. Paris: Presses Universitaires de France, 1994.

ChaVes, Rosan Costa; MARques, Antônio Luiz. Mudança organizacional no Setor Público: um estudo sobre o impacto das mudanças instituídas pelo Governo do Estado de Minas Gerais numa instituição pública estadual. In: XXX ENANPAD, 2000, Bahia. Anais... Salvador: ANPAD, 2000.

CHIN, W. W. The Partial Least Squares approach to structural equation modeling. In: MARCOULIDES, G. A. (Ed.). Modern Methods for business research. USA: Lawrence Erlbaum Associates, Inc., 1998, p. 295-336.

DE TONI, Deonir. Administração da imagem de produtos: desenvolvendo um instrumento para a configuração da imagem de produto. 2005. $268 \mathrm{f}$. Tese (Doutorado em Administração) - Escola de Administração, Universidade Federal do Rio Grande do Sul, Porto Alegre.

; MILAN, G. S.; SCHULER, M. Configuração de imagens de serviços: um estudo aplicado aos serviços de fisioterapia disponibilizados por um plano de saúde. ENANPAD, 2005.

DOBNI, D.; ZINKHAN, G. M. In search of brand image: a foundation analysis: Advances in Consumer Research. Duluth, v. 17, no 01, p. 110-119, 1990.

EysenCK, M. W.; KeANe, M. T. Psicologia cognitiva: um manual introdutório. Porto Alegre: Artes Médicas, 1994.

FORNELL, C.; LARCKER, D. F. Evaluating structural equation models with unobservable variables and measurement error. Journal of Marketing Research, v. 18, 1981.

GIL, Antonio Carlos. Métodos e técnicas de pesquisa social. 4. ed. São Paulo: Atlas, 1995. 
GolEMAN, D. Inteligência emocional: a teoria revolucionária que redefine o que é ser inteligente. Tradução de Marcos Santarrita. Rio de Janeiro: Objetiva, 1995. Tradução de Emotional intelligence.

GUARESCHI, P. Representações sociais: alguns comentários oportunos. In: SCHULZE, C. N. (Org.) Novas contribuições para a teorização e pesquisa em representação social. Coletâneas da Anpedd, v. 01, no 10, set. 1996.

JoVCHELOVITCH, S. Para uma tipologia dos saberes sociais: representações sociais, comunidade e cultura. In: SEMINÁRIO SOBRE REPRESENTAÇÕES SOCIAIS, 2000, Porto Alegre. Anais do Seminário sobre Representações Sociais. Porto Alegre: PUCRS, 2000.

LEVY, S. J. Symbols for sale. Harvard Business Review. Watertown, v. 37, no 04, p. 117-129, July/Aug. 1959.

Martineau, P. The personality of the retail store. Harvard Business Review. Watertown, v. 36, no 01, p. 47-55, jan./feb. 1958.

McDaniel, C.; Gates, R. Pesquisa de marketing. Tradução de James F. Suderland Cook, revisão técnica de Tânia Maria Vidigal Limeira. São Paulo: Thompson Learning, 2003.

MINAYO, M. O conceito de representações sociais dentro da sociologia clássica. In: JOVCHELOVITCH, S.; GUARESCHI, P. (Org.). Textos em representações sociais. Petrópolis: Vozes, 2003. p. 89-111.

Moscovicl, S. La Psychanalyse, son image et son public. Paris: Press Universitary de France, 1961.

A representação social da psicanálise. Rio de Janeiro: Zahar, 1978.

Representações Sociais: investigações em psicologia social. Editado em inglês por Gerard Duveen; traduzido do inglês por Pedrinho A. Guareschi. 5. ed. Petrópolis, RJ: Vozes, 2007.

SÁ, C. P. de. Sobre o núcleo central das representações sociais. Petrópolis, RJ: Vozes, 1996.

SANTAELla, Lúcia; Noth, Winfried. Imagem: cognição, semiótica e mídia. São Paulo: lluminuras, 2001.

SCHUleR, Maria. Administração da imagem organizacional: um método de configuração da imagem organizacional. Porto Alegre: UFRGS/EA/PPGA, 2000.

Sternberg, R. J. Psicologia cognitiva. Tradução de Maria Regina Borges Osório. Porto Alegre: Artmed, 2000. Tradução de Cognitive psychology.

Jussara Maria Canuto de Aquino

Possui Mestrado em Administração e é professora titular da Universidade Fumec.

Contato: Email: canuto.jussara@gmail.com

Luiz Antônio Antunes Teixeira

Possui Doutorado em Direção de Empresas pelo Instituto Estúdios Superiores de La Empresa (IESE), Espanha.

Contato: lantonio@fumec.br

Darly Fernando Andrade

É Doutor em Administração pela Universidade FUMEC e professor adjunto da Universidade Federal de Uberlândia. Contato: darly@ufu.br 


\section{RSP}

